\title{
Loss of Yes-associated Protein Represents an Aggressive Subtype of Colorectal Cancer
}

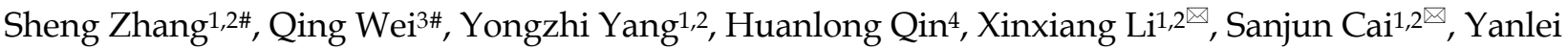 \\ $\mathrm{Ma}^{1,2}$ \\ 1. Department of Colorectal Surgery, Fudan University Shanghai Cancer Center, Shanghai, 200032, China \\ 2. Department of Oncology, Shanghai Medical College, Fudan University, Shanghai, 200032, China \\ 3. Department of Pathology, Shanghai Tenth People's Hospital, Tongii University, Shanghai, 200072, China. \\ 4. Department of GI Surgery, Shanghai Tenth People's Hospital, Tongji University, Shanghai 200072, China. \\ \# Sheng Zhang and Qing Wei contributed equally to this work. \\ $\square$ Corresponding authors: Yanlei Ma, MD, PhD, Sanjun Cai, MD, PhD and Xinxiang Li, MD, PhD, Department of Colorectal Surgery, Fudan University \\ Shanghai Cancer Center; Department of Oncology, Shanghai Medical College, Fudan University, 270 Dong'an Road, Shanghai, 200032, China. Email: \\ yanleima@fudan.edu.cn; sanjuncai@hotmail.com; li_xinxiang@hotmail.com \\ (c) Ivyspring International Publisher. This is an open access article distributed under the terms of the Creative Commons Attribution (CC BY-NC) license \\ (https://creativecommons.org/licenses/by-nc/4.0/). See http://ivyspring.com/terms for full terms and conditions.
}

Received: 2018.07.05; Accepted: 2018.10.27; Published: 2019.01.01

\begin{abstract}
Background: Yes-associated protein (YAP) is a downstream effecter of Hippo signaling pathway, and has been linked to the initiation and development of colorectal cancer (CRC). However, the clinical significance of YAP in CRC remains controversial. This study was designed to investigate the clinical significance of YAP in CRC.

Methods: We selected 206 eligible patients diagnosed with CRC from 2003 to 2007. Tissue microarray (TMA) blocks were made from 206 formalin-fixed paraffin-embedded CRC tissues and 158 corresponding normal colonic tissues. Using the TMA blocks, we performed immunohistochemical staining of YAP and assessed its expression status in different subcellular locations. The patients were divided into four groups according to the expression status of YAP in the cytoplasm and nucleus. Statistical analysis was performed to explore the correlation between YAP expression and clinicopathological features and overall survival (OS) in CRC patients.

Results: Our results showed that both cytoplasmic YAP and nuclear YAP were overexpressed in CRC tissues compared to normal colonic tissues. Complete loss of YAP expression in CRC was significantly correlated with larger tumor size $(p=0.023)$, proximal tumor location $(p=0.038)$, higher tumor grade $(p=0.022)$ and worse OS $(p<0.001)$. Univariate and multivariate Cox regression analyses revealed that complete loss of YAP expression was an independent indicator of poor prognosis in CRC $(p<0.001)$.

Conclusions: Loss of YAP expression correlates with poor prognosis and may represent a subgroup with more aggressive biological features in CRC.
\end{abstract}

Key words: Yes-associated protein, colorectal cancer, prognosis

\section{Background}

Colorectal cancer (CRC) is one of the most common malignant tumors worldwide [1]. In 2015, there were approximately 1.4 million new cases diagnosed with CRC, leading to 0.69 million deaths in China [2]. In mammals, the Hippo pathway is an important signaling pathway that regulates the cell regeneration, proliferation and apoptosis, and dysfunction of the Hippo pathway often contributes to the initiation and progression of many malignancies including CRC [3-6]. Yes-associated protein (YAP) is a critical component of the Hippo signaling pathway. Through a kinase cascade, the Hippo pathway targets YAP for phosphorylation, preventing its translocation to the nucleus, where it plays a role as a transcriptional co-activator [6-9]. YAP has been confirmed to be highly overexpressed and to participate in tumorigenesis in many human cancers, including CRC [10-12]. The oncogenic mechanism of YAP activity remains unclear. Some studies demonstrated that YAP suppresses the nuclear 
translocation of $\beta$-catenin by directly binding to it in the cytoplasm and inhibiting it $[9,11]$. In addition, YAP can also function as a stem cell regulator and play essential roles in maintaining stemness and tissue homeostasis $[13,14]$. However, the role of YAP in tumors remains controversial $[15,16]$. Some investigations showed that the overexpression of YAP was related to poor prognosis in a variety of cancers, including CRC $[10,17]$. In contrast, the other studies held the opposite viewpoint that YAP served as a tumor suppressor through effects on cell growth, apoptosis, maintenance of stemness, and inflammatory responses, and that the of loss of YAP expression correlated with poor prognosis[18-20]. To uncover the clinical significance of YAP expression in CRC, we performed immunohistochemistry (IHC) using tissue microarrays (TMAs) with more than 200 human CRC samples. We also studied the different expression levels of YAP between 158 pairs of CRC and non-tumor tissues using TMAs. This study may contribute to a better understanding of the dual role of $\mathrm{YAP}$ in malignancies.

\section{Methods}

\section{Patients and sample collection}

As the main purpose of this study was to investigate the clinical significance of YAP expression in CRC, we used the following exclusion criteria: 1) the presence of neoadjuvant chemo/radio-therapy; 2) the presence of hereditary or inflammation-associated CRC; 3) the pathological type was non-adenocarcinoma; 4) the follow-up information was unclear; 5) the cause of death was not related with CRC. Based on these exclusion criteria, 206 formalin-fixed paraffin-embedded tissue (FFPE) blocks from patients with CRC were obtained from the pathology department of Shanghai Tenth People's Hospital of Tongji University. All patients were of the same race, and underwent surgical resections from 2003 to 2007. Written informed consent was obtained from the patients, and the study was approved by the ethic committee of the hospital. Hematoxylin and eosin (H\&E) stained tissue sections from all cases were reviewed by two pathologists who were blinded to other data.

\section{TMA construction and clinicopathological features}

The construction of this TMA has been previously described in detail [21]. Briefly, a representative area was selected based on the $\mathrm{H} \& \mathrm{E}$ stained results. Using a punch machine, tissue cores with a $0.4 \mathrm{~mm}$ diameter were punched from each tumor tissue and paired normal tissue, and then placed into a $10 \mathrm{~mm} \times 8 \mathrm{~mm}$ recipient block. Each tissue core was assigned a unique tissue microarray location. Clinicopathological parameters included were age, sex, tumor size, tumor location, pathological grade, status of lymphatic invasion and TNM stage according to the $8^{\text {th }}$ edition of the AJCC classification. The survival data were collected from the hospital medical records and follow-up system.

\section{Immunohistochemistry}

For YAP immunohistochemistry staining, paraffin-embedded samples were cut into $4 \mu \mathrm{m}$ sections and placed on polylysine-coated slides. The staining process was performed as previously described with minor modifications [22]. Briefly, slides were baked at $60^{\circ} \mathrm{C}$ for $30 \mathrm{~min}$, deparaffinized in xylene, and rehydrated through a graded alcohol series. Antigen retrieval was achieved by microwaving in $10 \mathrm{mM}$ sodium citrate buffer $(\mathrm{pH}=$ 6.0) for approximately $10 \mathrm{~min}$. Endogenous peroxidase activity was blocked with $3 \%$ hydrogen peroxide in methanol at $37{ }^{\circ} \mathrm{C}$ for $15 \mathrm{~min}$, and nonspecific protein binding was blocked with $5 \%$ goat serum. The samples were incubated with a primary antibody against YAP (1:40 dilution; Cell Signaling Tech, \#14074) overnight in a humidity chamber at 4 ${ }^{\circ} \mathrm{C}$. The sections were washed three times with phosphate-buffered saline then, the samples were incubated with secondary antibody for $30 \mathrm{~min}$ at room temperature. Streptavidin was added, and the samples were incubated for $30 \mathrm{~min}$ at room temperature. Visualization was performed using DAB chromogen for 5-10 mins. All runs included a control with no primary antibody. Preimmune rabbit serum without any primary antibodies was used as a negative control. Positive control tissue was used according to the manufacturer's recommendation. Slides were counterstained with hematoxylin and mounted in a non-aqueous mounting medium.

\section{Interpretation of immunohistochemical staining}

All sample slides were scored separately by two pathologists blinded to the clinicopathological data. Five views were examined per slide, and 100 epithelial cells were observed per view at $\times 400$ magnification. Cytoplasmic YAP and nuclear YAP were scored according to the distribution, intensity, and percentage of positive cells as described previously with minor modifications [10]. Briefly, the staining intensity was scored as 0 (negative), 1 (weak), 2 (medium) or 3 (strong). The extent of staining was scored as $0(<5 \%), 1(5-25 \%), 2(26-50 \%), 3(51-75 \%)$ and $4(>75 \%)$, according to the percentages of the positive staining areas in relation to the effective area. The score of intensity and extent were multiplied to generate the staining score for each sample. Final 
staining scores $0-4$ and $5-12$ were considered negative and positive, respectively.

\section{Statistical analysis}

SPSS 22.0 (SPSS Inc., Chicago, IL, USA) and GraphPad Prism v.7 (La Jolla, CA, USA) was used for all statistical analyses. Chi-square tests were used to examine possible correlations between YAP expression and clinicopathologic factors. Survival analysis was performed using the Kaplan-Meier method, and the differences in survival between the subgroups were compared using the log-rank test. A multivariate analysis was performed using the Cox regression model to assess the association of different variables with colorectal cancer-specific mortality. All P-values were based on two- sided statistical analysis, and a P-value $<0.05$ was considered statistically significant.

\section{Results}

\section{Overexpression of YAP is common in CRC}

In the assessment of the status of nuclear and cytoplasmic YAP expression, 158 paired CRC tissues and normal tissues were analyzed. Our results showed that positive YAP staining was present in both the nuclear and cytoplasmic compartments (Figure 1). The rate of positive cytoplasmic YAP was $77.8 \%((25+98) / 158)$ in CRC tissues compared to $17.1 \%((25+2) / 158)$ in paired normal colonic tissue. The rate of positive nuclear YAP is $80.4 \%$ $((30+97) / 158)$ in CRC tissues compared to $20.9 \%$ $((30+3) / 158)$ in paired normal colonic tissues. The difference in YAP expression between CRC tissues and paired normal colonic tissues were statistically significant $(\mathrm{p}<0.001)$ (Table 1$)$.

Table 1. YAP staining status according to subcellular location in 158 paired CRC and normal tissues

\begin{tabular}{llllll}
\hline \multicolumn{5}{l}{ YAP staining status $(\mathrm{n}=158)$} & P value \\
\hline Tumor & + & + & - & - & \\
Normal & + & - & + & - & \\
Cytoplasm & 25 & 98 & 2 & 33 & $<0.001$ \\
Nucleus & 30 & 97 & 3 & 28 & $<0.001$ \\
\hline McNemar test. \\
Notes : "+" means positive while "-" means negative.
\end{tabular}

\section{Correlation between YAP expression and clinicopathologic parameters in CRC}

The median age of the 206 CRC patients was 69 years, ranging from 37 to 87 years old. In total, 118 $(57.3 \%)$ were male, and $88(42.7 \%)$ were female. The tumor location was divided into the proximal colon (cecum to transverse colon), the distal colon (splenic flexure to sigmoid colon), and the rectum based on clinical, pathological, and epidemiological studies

[23-25]. Tumor grade was categorized as low vs. high $(>50 \%$ vs. $\leq 50 \%$ gland formation). The maximum diameter of the tumor was defined as the tumor size. The median tumor size was $4.5 \mathrm{~cm}$, which was set as the cut-off point. All patients were divided into the following four groups according to the expression status of YAP in the cytoplasm and the nucleus: cytoplasmic positive and nuclear positive $(\mathrm{C}(+) \mathrm{N}(+))$, cytoplasmic positive and nuclear negative $(\mathrm{C}(+) \mathrm{N}(-))$, cytoplasmic negative and nuclear positive $(\mathrm{C}(-) \mathrm{N}(+))$, and cytoplasmic negative and nuclear negative $(\mathrm{C}(-) \mathrm{N}(-))$ (Figure 1). The correlations between YAP staining status and the clinicopathologic parameters were analyzed. As described in Table 2, there were significant differences in tumor size $(\mathrm{p}=0.023)$, tumor location $(\mathrm{p}=0.038)$ and tumor grade $(\mathrm{p}=0.022)$, but no significant differences in age, sex, lymphatic invasion, and TNM staging among these four groups.

Table 2. Characteristics of CRC cases according to YAP staining status

\begin{tabular}{|c|c|c|c|c|c|c|}
\hline \multirow[t]{2}{*}{ Characteristics } & \multirow{2}{*}{$\begin{array}{l}\text { All cases } \\
(n=206)\end{array}$} & \multicolumn{4}{|c|}{ YAP staining status } & \multirow{2}{*}{$\begin{array}{l}\mathrm{P} \\
\text { value }\end{array}$} \\
\hline & & $\mathrm{C}(+) \mathrm{N}(+)$ & $\mathrm{C}(+) \mathrm{N}(-)$ & $\mathrm{C}(-) \mathrm{N}(+)$ & $\mathrm{C}(-) \mathrm{N}(-)$ & \\
\hline & & $(n=135)$ & $(n=18)$ & $(n=22)$ & $(n=31)$ & \\
\hline \multicolumn{7}{|l|}{ Age (years) } \\
\hline$\geq 60$ & $145(70.4 \%)$ & $\begin{array}{l}101 \\
(74.8 \%)\end{array}$ & $\begin{array}{l}12 \\
(66.7 \%)\end{array}$ & $\begin{array}{l}16 \\
(72.7 \%)\end{array}$ & $\begin{array}{l}16 \\
(51.6 \%)\end{array}$ & 0.082 \\
\hline$<60$ & $61(29.6 \%)$ & $\begin{array}{l}34 \\
(25.2 \%)\end{array}$ & $\begin{array}{l}6 \\
(33.3 \%)\end{array}$ & $\begin{array}{l}6 \\
(27.3 \%)\end{array}$ & $\begin{array}{l}15 \\
(48.4 \%)\end{array}$ & \\
\hline \multicolumn{7}{|l|}{ Sex } \\
\hline Men & $118(57.2 \%)$ & $\begin{array}{l}80 \\
(59.3 \%)\end{array}$ & $\begin{array}{l}9 \\
(50.0 \%)\end{array}$ & $\begin{array}{l}10 \\
(45.5 \%)\end{array}$ & $\begin{array}{l}19 \\
(61.3 \%)\end{array}$ & 0.559 \\
\hline Women & $88(42.8 \%)$ & $\begin{array}{l}55 \\
(40.7 \%)\end{array}$ & $\begin{array}{l}9 \\
(50.0 \%)\end{array}$ & $\begin{array}{l}12 \\
(54.5 \%)\end{array}$ & $\begin{array}{l}12 \\
(38.7 \%)\end{array}$ & \\
\hline \multicolumn{7}{|l|}{ Tumor size } \\
\hline$<4.5 \mathrm{~cm}$ & $101(49 \%)$ & $\begin{array}{l}74 \\
(54.8 \%)\end{array}$ & $\begin{array}{l}7 \\
(38.9 \%)\end{array}$ & $\begin{array}{l}12 \\
(55.5 \%)\end{array}$ & $\begin{array}{l}8 \\
(25.8 \%)\end{array}$ & 0.023 \\
\hline$\geq 4.5 \mathrm{~cm}$ & 105 (51\%) & $\begin{array}{l}61 \\
(45.2 \%)\end{array}$ & $\begin{array}{l}11 \\
(61.1 \%)\end{array}$ & $\begin{array}{l}10 \\
(45.5 \%)\end{array}$ & $\begin{array}{l}23 \\
(74.2 \%)\end{array}$ & \\
\hline \multicolumn{7}{|l|}{ Tumor location } \\
\hline Proximal colon & $71(34.4 \%)$ & $\begin{array}{l}36 \\
(26.7 \%)\end{array}$ & $\begin{array}{l}8 \\
(44.4 \%)\end{array}$ & $\begin{array}{l}9 \\
(40.9 \%)\end{array}$ & $\begin{array}{l}18 \\
(58.1 \%)\end{array}$ & 0.038 \\
\hline Distal colon & $66(29.2 \%)$ & $\begin{array}{l}50 \\
(37.0 \%)\end{array}$ & $\begin{array}{l}4 \\
(22.2 \%)\end{array}$ & $\begin{array}{l}7 \\
(31.8 \%)\end{array}$ & $\begin{array}{l}5 \\
(16.1 \%)\end{array}$ & \\
\hline Rectum & $69(30.4 \%)$ & $\begin{array}{l}49 \\
(36.3 \%)\end{array}$ & $\begin{array}{l}6 \\
(33.3 \%)\end{array}$ & $\begin{array}{l}6 \\
(27.3 \%)\end{array}$ & $\begin{array}{l}8 \\
(25.8 \%)\end{array}$ & \\
\hline \multicolumn{7}{|l|}{ Grade } \\
\hline Low & $150(72.8 \%)$ & $\begin{array}{l}106 \\
(78.5 \%)\end{array}$ & $\begin{array}{l}12 \\
(66.7 \%)\end{array}$ & $\begin{array}{l}16 \\
(72.7 \%)\end{array}$ & $\begin{array}{l}16 \\
(51.6 \%)\end{array}$ & 0.022 \\
\hline High & $56(27.2 \%)$ & $\begin{array}{l}29 \\
(21.5 \%)\end{array}$ & $\begin{array}{l}6 \\
(33.3 \%)\end{array}$ & $\begin{array}{l}6 \\
(27.3 \%)\end{array}$ & $\begin{array}{l}15 \\
(48.4 \%)\end{array}$ & \\
\hline \multicolumn{7}{|l|}{$\begin{array}{l}\text { Lymphatic } \\
\text { invasion }\end{array}$} \\
\hline Negative & $133(64.5 \%)$ & $\begin{array}{l}92 \\
(68.1 \%)\end{array}$ & $\begin{array}{l}13 \\
(72.2 \%)\end{array}$ & $\begin{array}{l}13 \\
(59.1 \%)\end{array}$ & $\begin{array}{l}15 \\
(48.4 \%)\end{array}$ & 0.168 \\
\hline Positive & $73(35.5 \%)$ & $\begin{array}{l}43 \\
(31.9 \%)\end{array}$ & $\begin{array}{l}5 \\
(27.8 \%)\end{array}$ & $\begin{array}{l}9 \\
(40.9 \%)\end{array}$ & $\begin{array}{l}16 \\
(51.6 \%)\end{array}$ & \\
\hline \multicolumn{7}{|l|}{ Disease stage } \\
\hline $\mathrm{I} / \mathrm{II}$ & $129(62.6 \%)$ & $\begin{array}{l}89 \\
(65.9 \%)\end{array}$ & $\begin{array}{l}12 \\
(66.7 \%)\end{array}$ & $\begin{array}{l}13 \\
(59.1 \%)\end{array}$ & $\begin{array}{l}15 \\
(48.4 \%)\end{array}$ & 0.314 \\
\hline III/IV & $77(37.4 \%)$ & $\begin{array}{l}46 \\
(34.1 \%)\end{array}$ & $\begin{array}{l}6 \\
(33.3 \%)\end{array}$ & $\begin{array}{l}9 \\
(40.9 \%)\end{array}$ & $\begin{array}{l}16 \\
(51.6 \%)\end{array}$ & \\
\hline \multicolumn{7}{|c|}{$\begin{array}{l}\text { Pearson's chi-square test. } \\
\text { Abbreviation : } \mathrm{C}(+) \mathrm{N}(+) \text { :Cytoplasmic positive and nuclear positive; } \mathrm{C}(+) \mathrm{N}(-) \text { : } \\
\text { Cytoplasmic positive and nuclear negative; }\end{array}$} \\
\hline $\begin{array}{l}\mathrm{C}(-) \mathrm{N}(+) \text { : Cytopl } \\
\text { negative and nuc }\end{array}$ & $\begin{array}{l}\text { smic negative } \\
\text { ear negative. }\end{array}$ & d nuclear $\mathrm{p}$ & ositive; $\mathrm{C}$ & $(-) N(-): C y$ & toplasmic & \\
\hline
\end{tabular}


The group with complete loss of YAP expression $(\mathrm{C}(-) \mathrm{N}(-))$ had a higher proportion of large tumor size $(74.2 \%)$, tumors in the proximal location $(58.1 \%)$, and tumors with high grade $(48.4 \%)$ than the other three groups.

\section{Prognostic significance of YAP staining status in CRC}

To determine the prognostic significance of YAP expression in $\mathrm{CRC}$, we attempted to relate YAP expression to the clinical outcomes. The median follow-up time was 129 months, ranging from 5 to 174
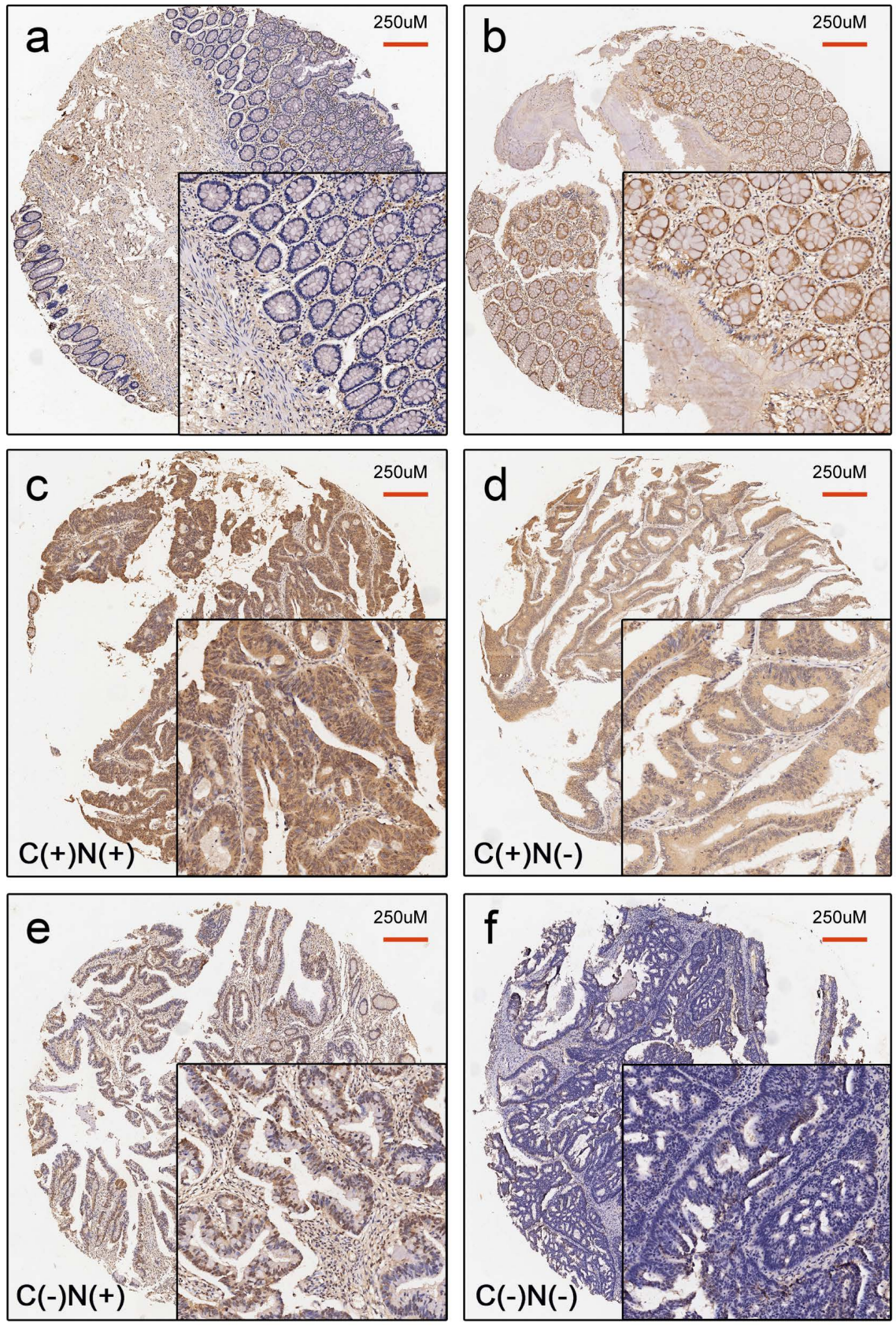

Figure 1. Representative image for YAP staining status in normal colonic tissue (a-b) and CRC tissue (c-f). a. Negative YAP expression in normal colonic tissue. b. Positive YAP expression in normal colonic tissue. c. $C(+) N(+)$ : positive YAP expression in both the cytoplasm and nucleus in CRC tissues. d. C(+)N(-): positive YAP expression only in cytoplasm in CRC tissues. e. $\mathrm{C}(-) \mathrm{N}(+)$ : positive YAP expression only in the nucleus in CRC tissues. $\mathrm{f}$. C(-)N(-): Complete loss of YAP expression in CRC tissues. 
a

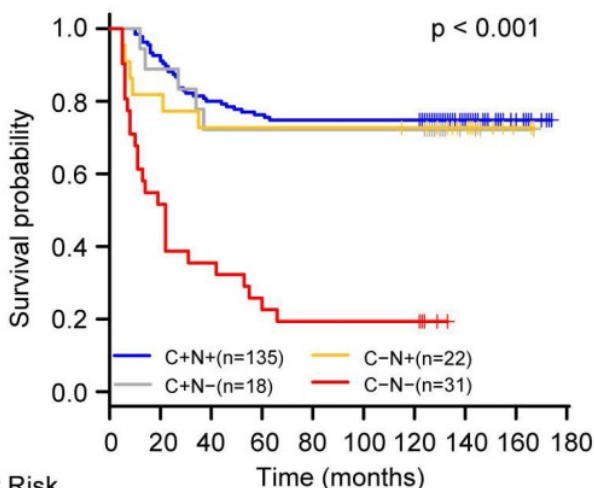

No. At Risk

$\mathrm{C}+\mathrm{N}+(\mathrm{n}=135) 13512510810310110110147 \quad 17 \quad 0$

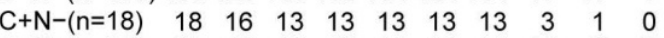

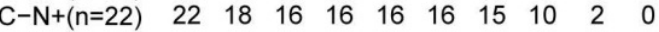

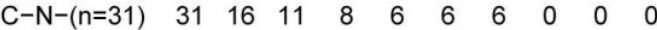

b

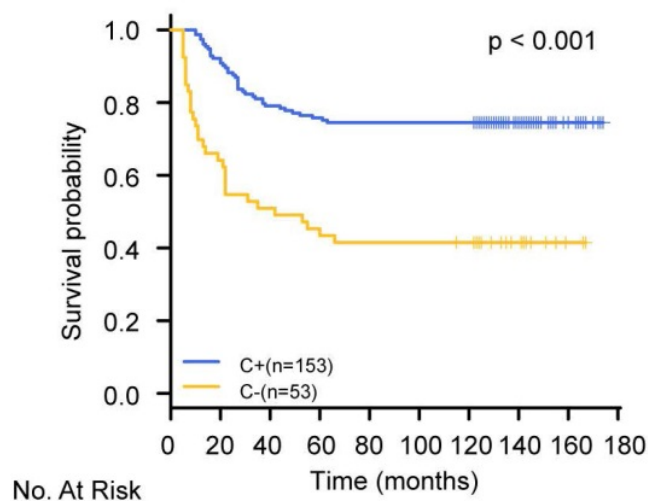

$\mathrm{C}+(\mathrm{n}=153) 15314112111611411411450 \quad 18 \quad 0$ C-(n=53) $\begin{array}{llllllllllll}53 & 34 & 27 & 24 & 22 & 22 & 21 & 10 & 2 & 0\end{array}$

C

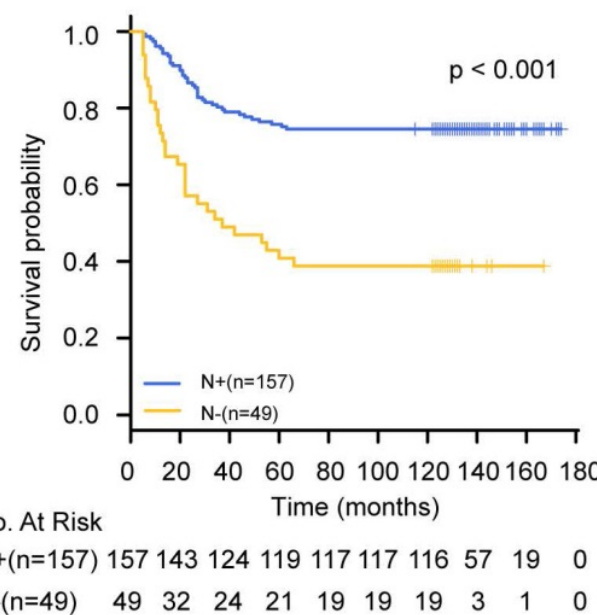

Figure 2. Kaplan-Meier survival curves for CRC patients categorized by YAP staining status. a. $\mathrm{C}+\mathrm{N}+$ : cytoplasmic positive and nuclear positive; $\mathrm{C}+\mathrm{N}$-: cytoplasmic positive and nuclear negative; $\mathrm{C}-\mathrm{N}+$ : cytoplasmic negative and nuclear positive; C-N-: complete loss of YAP expression. b. C+: cytoplasmic positive regardless of nuclear staining status; C-: cytoplasmic negative regardless of nuclear staining status. c. $\mathrm{N}+$ : nuclear positive regardless of cytoplasmic staining status; $\mathrm{N}$-: nuclear negative regardless of cytoplasmic staining status.

Statistically significant differences in OS were observed among these four groups of patients. The group with complete loss of YAP expression $(\mathrm{C}(-) \mathrm{N}(-))$ had the worst prognosis in terms of OS compared to the other three groups $(\mathrm{P}<0.001)$ (Figure 2a). If the whole population was divided into two subgroups according to the expression state of YAP in the cytoplasm or nucleus, the survival analysis results also showed that the loss of YAP was associated with poor prognosis whether it was lost in the cytoplasm or in the nucleus (Figure 2b-2c). Furthermore, univariate Cox regression model analysis revealed that tumor size $(p=0.03)$, proximal colon location $(p=0.04)$, advanced TNM stage $(\mathrm{p}<0.001)$, high grade $(\mathrm{p}<0.001)$, and complete loss of YAP expression $(p<0.001)$ were associated with higher risks of colorectal cancer-specific mortality (Table 3). These five factors were included in the multivariate Cox regression model and the results demonstrated that advanced TNM stage $(\mathrm{HR}=2.90 ; 95 \% \mathrm{CI}=1.78-4.75 ; \mathrm{p}<0.001)$, high tumor grade $(\mathrm{HR}=1.88 ; 95 \% \mathrm{CI}=1.14-3.11 ; \mathrm{p}=0.014)$, and complete loss of YAP expression $(\mathrm{HR}=3.93$; 95\% CI=2.18-7.07; $\mathrm{p}<0.001$ ) were independent poor prognostic factors for CRC (Table 3 ).

Table 3. Cox regression analyses for colorectal cancer-specific mortality

\begin{tabular}{|c|c|c|c|c|}
\hline \multirow[t]{2}{*}{ Characteristics } & \multicolumn{2}{|l|}{ Univariate analysis } & \multicolumn{2}{|c|}{ Multivariate analysis\# } \\
\hline & $\mathrm{HR}(95 \% \mathrm{CI})$ & Pvalue & $\mathrm{HR}(95 \% \mathrm{CI})$ & Pvalue \\
\hline Age $<60$ (vs. Age $\geq 60$ ) & $1.59(0.99$ to 2.58$)$ & 0.060 & & \\
\hline Male (vs. female) & $1.00(0.62$ to 1.60$)$ & 0.100 & & \\
\hline $\begin{array}{l}\text { Tumor size } \geq 4.5 \mathrm{~cm} \text { ( vs. } \\
\text { size }<4.5 \mathrm{~cm} \text { ) }\end{array}$ & 1.70 (1.05 to 2.75$)$ & 0.030 & $\begin{array}{l}1.151(0.674 \text { to } \\
1.966)\end{array}$ & 0.606 \\
\hline \multicolumn{5}{|l|}{ Tumor location } \\
\hline $\begin{array}{l}\text { Distal colon vs. } \\
\text { Proximal colon }\end{array}$ & $0.50(0.26$ to 0.98$)$ & 0.040 & $\begin{array}{l}0.661(0.332 \text { to } \\
1.313)\end{array}$ & 0.237 \\
\hline $\begin{array}{l}\text { Rectum vs. Proximal } \\
\text { colon }\end{array}$ & $1.39(0.82$ to 2.35$)$ & 0.220 & & \\
\hline $\begin{array}{l}\text { Tumor stage III-IV (vs. } \\
\text { stage I, II) }\end{array}$ & 3.24 (2.01 to 5.24$)$ & 0.000 & $2.90(1.78$ to 4.75$)$ & 0.000 \\
\hline Grade (high vs. low ) & $2.69(1.67$ to 4.31$)$ & 0.000 & 1.88 (1.14 to 3.11$)$ & 0.014 \\
\hline $\begin{array}{l}\text { Chemotherapy(yes vs. } \\
\text { no) }\end{array}$ & $1.23(0.76$ to 1.99$)$ & 0.400 & & \\
\hline \multicolumn{5}{|l|}{ YAP staining status } \\
\hline $\mathrm{C}(+) \mathrm{N}(+)$ & 1 (reference) & & & \\
\hline $\mathrm{C}(+) \mathrm{N}(-)$ & $1.13(0.44$ to 2.89$)$ & 0.800 & $1.02(0.40$ to 2.63$)$ & 0.960 \\
\hline $\mathrm{C}(-) \mathrm{N}(+)$ & 1.21 (0.51 to 2.87$)$ & 0.670 & $1.26(0.53$ to 3.01$)$ & 0.604 \\
\hline $\mathrm{C}(-) \mathrm{N}(-)$ & 5.85 (3.48 to 9.85$)$ & 0.000 & 3.93 (2.18 to 7.07$)$ & 0.000 \\
\hline
\end{tabular}

\section{Discussion}

First, we detected the expression of YAP in colorectal adenocarcinoma and paired normal colonic mucosa by TMAs. The results demonstrated that YAP was significantly overexpressed in cancer tissues in 
comparison to normal colonic tissues, whether in the cytoplasm or in the nucleus. We rarely observed positive staining of YAP in the cytoplasm without nuclear expression. This finding was consistent with the results of several previous studies [11, 22, 26-28], which further confirmed the viewpoint that enhanced YAP expression might be a common event in the carcinogenesis of CRC.

Then, we analyzed the clinical significance of YAP in CRC. It is widely accepted that dysfunction of Hippo signaling pathway leads to abnormal accumulation of YAP within the cytoplasm and translocation of cytoplasmic YAP to the nucleus, where it functions as a transcriptional co-activator [5, 29]. Barry et al. [18] found that YAP nuclear localization was correlated with activation of the Wnt signaling pathway, whereas YAP cytoplasmic localization inhibited the Wnt signaling pathway which played an essential role in colorectal carcinogenesis [30]. This suggests that different subcellular localization of YAP may produce different biological effects. Based on this, the study population was divided into four subgroups according to the expression status of the YAP protein in the cytoplasm and nucleus. Results showed that complete loss of YAP expression correlated with proximal colon location, high tumor grade, and larger tumor size. Accumulating evidence shows that there are differences in the molecular pathological mechanism, clinical prognosis and epidemiology between proximal colon cancer and distal colon cancer [23-25]. Our study shows that the loss of YAP expression is more frequent in the proximal colon, which may suggest that loss of YAP is a molecular epidemiological characteristic of proximal colon cancer. In addition, the loss of YAP was also correlated with high tumor grade and larger tumor size, which was consistent with the results of another study [18].

However, there was a disagreement with the prognostic value of YAP in various types of cancers including CRC. A meta-analysis including 2067 patients from 21 studies showed that positive YAP expression contributes to poor OS in patients with various malignancies [31]. It is well documented that YAP expression is positively correlated with poor OS in CRC [10,17, 32-34], hepatocellular carcinoma [35], non-small cell lung carcinoma [36], and gastric cancer [37]. In contrast, some studies observed a contradictory result in CRC [18] and breast cancer [20, 38]. Our results showed that complete deletion of YAP significantly increased the risk of colorectal cancer-specific mortality and served as an independent poor prognostic factor, which was in line with the result of a previous report [18]. The reason for this lack of consensus may be related to some confounding factors such as different sample size and races included, different enrollment and exclusion criteria, and different lengths of follow-up periods. To accurately investigate the clinical significance of YAP expression in CRC, we established strict enrollment criteria to exclude possible confounding factors. These exclusion criteria included the presence of rare pathological types, the presence of preoperative treatment, hereditary or inflammation-associated CRC, unclear prognostic data, and non-tumor related deaths. It is worth mentioning that the median follow-up period of this study was more than 10 years. Under these conditions, the prognostic value of YAP observed in this study seems to be more reliable, although limitations still exist due to the lack of validation from multi-center cohorts. Currently, most studies consider YAP to be an oncogene that promotes cancer development, and these cancer-promoting mechanisms are associated with anti-apoptosis, epithelia-mesenchymal transition, cancer stem cells, and drug resistance [10, 11, 39-43]. In contrast, some studies have reported that YAP can act as a tumor suppressor in various cancers, such as breast cancer [20], hematological cancers [19] and CRC [44]. Barry et al.[18] noted that overexpression of YAP led to inhibition of the Wnt signaling pathway and intestinal stem cell expansion, which suggests a tumor suppressor role of YAP. In addition, YAP was described as an inducer of apoptosis in response to DNA damage by enhancing the ability of p73 in CRC, indicating that YAP might play a critical role in tumor suppression [45-48]. Therefore, it is impossible to simply categorize YAP as either a tumor promoter or a tumor suppressor $[15,16]$. The development of CRC is a complex process involving multiple factors, and the cross-talk between Hippo signaling pathway and the other pathways in tumors may affect the conversion of the role of YAP in different stages and different biological environments. Further investigation into the mechanisms responsible for the dual role of YAP may provide us with a new perspective on the prevention, early diagnosis, prediction of prognosis and treatment of CRC.

\section{Conclusions}

In conclusion, overexpression of $\mathrm{YAP}$ is a common event in the carcinogenesis of CRC. Complete loss of YAP expression correlates with proximal tumor location, larger tumor size, high tumor grade, and poor prognosis in terms of OS in CRC. We may infer a dual role of YAP in the development of CRC, and the deletion of YAP in CRC represents a subtype with more aggressive biological features. 


\section{Abbreviations}

CRC: colorectal cancer; OS: overall survival; YAP: Yes-associated protein; FFPE: formalin-fixed paraffin-embedded tissue; IHC: immunohistochemistry. TMA: Tissue microarray; H\&E: Hematoxylin and eosin; $\mathrm{C}(+) \mathrm{N}(+)$ : cytoplasmic positive and nuclear positive; $\mathrm{C}(+) \mathrm{N}(-)$ : cytoplasmic positive and nuclear negative; $\mathrm{C}(-) \mathrm{N}(+)$ : cytoplasmic negative and nuclear positive; $\mathrm{C}(-) \mathrm{N}(-)$ : cytoplasmic negative and nuclear negative; HR: hazard ration; $\mathrm{CI}$ : Confidence interval.

\section{Supplementary Material}

Supplementary figure.

http://www.jcancer.org/v10p0689s1.pdf

\section{Acknowledgements}

\section{Funding}

This work was supported by grants from the Fudan Outstanding Young Talent Training Plan (YJYQ201601), Sponsored by Shanghai Pujiang Program (17PJD007), Shanghai Youth Top-notch Talent Support Program (Yanlei Ma) and National Natural Science Foundation of China (NSFC1631).

\section{Authors' contributions}

SZ, QW, and YM designed the experiments, analyzed data and prepared the manuscript. HL and QW provided the CRC clinical samples. YM, SC, YY and $\mathrm{XL}$ designed and were the overseers of the entire study. All authors read and approved the final manuscript for publication.

\section{Ethics approval and consent to participate}

The study was conducted in accordance with the Declaration of Helsinki principles. It was approved by the Human Research Ethics Committee of related medical center. Written informed consent for the use of tissues for research was taken from patients at the time of procurement of tumor specimens.

\section{Competing Interests}

The authors have declared that no competing interest exists.

\section{References}

1. Torre LA, Bray F, Siegel RL, Ferlay J, Lortet-Tieulent J, Jemal A. Global cancer statistics, 2012. CA Cancer J Clin. 2015; 65: 87-108.

2. Chen W, Zheng R, Baade PD, Zhang S, Zeng H, Bray F, et al. Cancer statistics in China, 2015. CA Cancer J Clin. 2016; 66: 115-32.

3. Wierzbicki PM, Rybarczyk A. The Hippo pathway in colorectal cancer. Folia Histochem Cytobiol. 2015; 53: 105-19.

4. Yu FX, Zhao B, Guan KL. Hippo Pathway in Organ Size Control, Tissue Homeostasis, and Cancer. Cell. 2015; 163: 811-28.

5. Pan D. The hippo signaling pathway in development and cancer. Dev Cell. 2010; 19: 491-505.

6. Zhao B, Li L, Lei Q, Guan KL. The Hippo-YAP pathway in organ size control and tumorigenesis: an updated version. Genes Dev. 2010; 24: 862-74.
7. Lamar JM, Stern P, Liu H, Schindler JW, Jiang ZG, Hynes RO. The Hippo pathway target, YAP, promotes metastasis through its TEAD-interaction domain. Proc Natl Acad Sci U S A. 2012; 109: E2441-50.

8. Meng Z, Moroishi T, Guan KL. Mechanisms of Hippo pathway regulation. Genes Dev. 2016; 30: 1-17.

9. Imajo M, Miyatake K, Iimura A, Miyamoto A, Nishida E. A molecular mechanism that links Hippo signalling to the inhibition of Wnt/beta-catenin signalling. EMBO J. 2012; 31: 1109-22.

10. Wang L, Shi S, Guo Z, Zhang X, Han S, Yang A, et al. Overexpression of YAP and TAZ is an independent predictor of prognosis in colorectal cancer and related to the proliferation and metastasis of colon cancer cells. PLoS One. 2013; 8: e65539.

11. Konsavage WM, Jr., Kyler SL, Rennoll SA, Jin G, Yochum GS. Wnt/beta-catenin signaling regulates Yes-associated protein (YAP) gene expression in colorectal carcinoma cells. J Biol Chem. 2012; 287: 11730-9.

12. Avruch J, Zhou D, Bardeesy N. YAP oncogene overexpression supercharges colon cancer proliferation. Cell Cycle. 2012; 11: 1090-6.

13. Ramos A, Camargo FD. The Hippo signaling pathway and stem cell biology. Trends Cell Biol. 2012; 22: 339-46.

14. Barry ER, Camargo FD. The Hippo superhighway: signaling crossroads converging on the Hippo/Yap pathway in stem cells and development. Curr Opin Cell Biol. 2013; 25: 247-53

15. Ou C, Sun Z, Li S, Li G, Li X, Ma J. Dual roles of yes-associated protein (YAP) in colorectal cancer. Oncotarget. 2017; 8: 75727-41.

16. Li VS, Clevers $\mathrm{H}$. Intestinal regeneration: YAP-tumor suppressor and oncoprotein? Curr Biol. 2013; 23: R110-2.

17. Wang $\mathrm{Y}, \mathrm{Xie} \mathrm{C}, \mathrm{Li} \mathrm{Q}, \mathrm{Xu} \mathrm{K}$, Wang E. Clinical and prognostic significance of Yes-associated protein in colorectal cancer. Tumour Biol. 2013; 34: 2169-74.

18. Barry ER, Morikawa T, Butler BL, Shrestha K, de la Rosa R, Yan KS, et al. Restriction of intestinal stem cell expansion and the regenerative response by YAP. Nature. 2013; 493: 106-10.

19. Cottini F, Hideshima T, Xu C, Sattler M, Dori M, Agnelli L, et al. Rescue of Hippo coactivator YAP1 triggers DNA damage-induced apoptosis in hematological cancers. Nat Med. 2014; 20: 599-606.

20. Yuan M, Tomlinson V, Lara R, Holliday D, Chelala C, Harada T, et al. Yes-associated protein (YAP) functions as a tumor suppressor in breast. Cell Death Differ. 2008; 15: 1752-9.

21. Sauter G, Simon R, Hillan K. Tissue microarrays in drug discovery. Nat Rev Drug Discov. 2003; 2: 962-72.

22. Steinhardt AA, Gayyed MF, Klein AP, Dong J, Maitra A, Pan D, et al. Expression of Yes-associated protein in common solid tumors. Hum Pathol. 2008; 39: 1582-9.

23. Iacopetta B. Are there two sides to colorectal cancer? Int J Cancer. 2002; 101: 403-8.

24. Gervaz P, Bucher P, Morel P. Two colons-two cancers: paradigm shift and clinical implications. J Surg Oncol. 2004; 88: 261-6.

25. Carethers JM. One colon lumen but two organs. Gastroenterology. 2011; 141: 411-2.

26. Ling HH, Kuo CC, Lin BX, Huang YH, Lin CW. Elevation of YAP promotes the epithelial-mesenchymal transition and tumor aggressiveness in colorectal cancer. Exp Cell Res. 2017; 350: 218-25.

27. Tschaharganeh DF, Chen X, Latzko P, Malz M, Gaida MM, Felix K, et al Yes-associated protein up-regulates Jagged-1 and activates the Notch pathway in human hepatocellular carcinoma. Gastroenterology. 2013; 144: 1530-42 e12.

28. Zhou D, Zhang $\mathrm{Y}, \mathrm{Wu} \mathrm{H}$, Barry E, Yin $\mathrm{Y}$, Lawrence E, et al. Mst1 and Mst2 protein kinases restrain intestinal stem cell proliferation and colonic tumorigenesis by inhibition of Yes-associated protein (Yap) overabundance. Proc Natl Acad Sci U S A. 2011; 108: E1312-20.

29. Huang J, Wu S, Barrera J, Matthews K, Pan D. The Hippo signaling pathway coordinately regulates cell proliferation and apoptosis by inactivating Yorkie, the Drosophila Homolog of YAP. Cell. 2005; 122: 421-34.

30. Novellasdemunt L, Antas P, Li VS. Targeting Wnt signaling in colorectal cancer. A Review in the Theme: Cell Signaling: Proteins, Pathways and Mechanisms. Am J Physiol Cell Physiol. 2015; 309: C511-21.

31. Sun $Z, X u R, L i X$, Ren $W$, Ou C, Wang $Q$, et al. Prognostic Value of Yes-Associated Protein 1 (YAP1) in Various Cancers: A Meta-Analysis. PLoS One. 2015; 10: e0135119.

32. Lee KW, Lee SS, Kim SB, Sohn BH, Lee HS, Jang HJ, et al. Significant association of oncogene YAP1 with poor prognosis and cetuximab resistance in colorectal cancer patients. Clin Cancer Res. 2015; 21: 357-64.

33. Kim DH, Kim SH, Lee OJ, Huang SM, Kwon JL, Kim JM, et al. Differential expression of Yes-associated protein and phosphorylated Yes-associated protein is correlated with expression of Ki-67 and phospho-ERK in colorectal adenocarcinoma. Histol Histopathol. 2013; 28: 1483-90.

34. Touil Y, Igoudjil W, Corvaisier M, Dessein AF, Vandomme J, Monte D, et al. Colon cancer cells escape 5FU chemotherapy-induced cell death by entering stemness and quiescence associated with the c-Yes/YAP axis. Clin Cancer Res. 2014; 20: 837-46.

35. Xu MZ, Yao TI, Lee NP, Ng IO, Chan YT, Zender L, et al Yes-associated protein is an independent prognostic marker in hepatocellular carcinoma. Cancer. 2009; 115: 4576-85.

36. Wang $\mathrm{Y}$, Dong $\mathrm{Q}$, Zhang $\mathrm{Q}$, Li Z, Wang E, Oiu X. Overexpression of yes-associated protein contributes to progression and poor prognosis of non-small-cell lung cancer. Cancer Sci. 2010; 101: 1279-85. 
37. Kang W, Tong JH, Chan AW, Lee TL, Lung RW, Leung PP, et al. Yes-associated protein 1 exhibits oncogenic property in gastric cancer and its nuclear accumulation associates with poor prognosis. Clin Cancer Res. 2011; 17: 2130-9.

38. Yu SJ, Hu JY, Kuang XY, Luo JM, Hou YF, Di GH, et al. MicroRNA-200a promotes anoikis resistance and metastasis by targeting YAP1 in human breast cancer. Clin Cancer Res. 2013; 19: 1389-99.

39. Vigneron AM, Ludwig RL, Vousden KH. Cytoplasmic ASPP1 inhibits apoptosis through the control of YAP. Genes Dev. 2010; 24: 2430-9.

40. Shao DD, Xue W, Krall EB, Bhutkar A, Piccioni F, Wang X, et al. KRAS and YAP1 converge to regulate EMT and tumor survival. Cell. 2014; 158: 171-84.

41. Blandino G, Di Agostino S. New therapeutic strategies to treat human cancers expressing mutant p53 proteins. J Exp Clin Cancer Res. 2018; 37: 30.

42. Lian I, Kim J, Okazawa H, Zhao J, Zhao B, Yu J, et al. The role of YAP transcription coactivator in regulating stem cell self-renewal and differentiation. Genes Dev. 2010; 24: 1106-18

43. Song S, Honjo S, Jin J, Chang SS, Scott AW, Chen Q, et al. The Hippo Coactivator YAP1 Mediates EGFR Overexpression and Confers Chemoresistance in Esophageal Cancer. Clin Cancer Res. 2015; 21: 2580-90.

44. Levy D, Adamovich Y, Reuven N, Shaul Y. The Yes-associated protein 1 stabilizes p73 by preventing Itch-mediated ubiquitination of p73. Cell Death Differ. 2007; 14: 743-51.

45. Lapi E, Di Agostino S, Donzelli S, Gal H, Domany E, Rechavi G, et al. PML, $\mathrm{YAP}$, and $\mathrm{p} 73$ are components of a proapoptotic autoregulatory feedback loop. Mol Cell. 2008; 32: 803-14.

46. Bertini E, Oka T, Sudol M, Strano S, Blandino G. YAP: at the crossroad between transformation and tumor suppression. Cell Cycle. 2009; 8: 49-57.

47. Strano S, Monti O, Pediconi N, Baccarini A, Fontemaggi G, Lapi E, et al. The transcriptional coactivator Yes-associated protein drives p73 gene-target specificity in response to DNA Damage. Mol Cell. 2005; 18: 447-59.

48. Matallanas D, Romano D, Yee K, Meissl K, Kucerova L, Piazzolla D, et al RASSF1A elicits apoptosis through an MST2 pathway directing proapoptotic transcription by the p73 tumor suppressor protein. Mol Cell. 2007; 27: 962-75. 